\section{Arctic rockets give glimpse of the atmosphere's top layers}

Quirin Schiermeier, Spitsbergen

A series of rocket-borne atmospheric reconnaissance missions in the Arctic Circle is yielding potentially valuable data on the little-known thermodynamics of the middle and upper atmosphere.

On 8 July a German-Norwegian team launched the third and final mission in the ROMA (Rocket-borne Observation in the Middle Atmosphere) project. The probe blasted off from an international research base at Ny Ålesund, on the Norwegian island of Spitsbergen.

ROMA's rocket-borne, returnable probes measure temperature, density and ion concentration on their ascent to altitudes of about 105 kilometres. The $€ 250,000$ (US\$280,000) instruments are launched on 6.5-metre, solid-fuelled rockets — which researchers inherited when they were discarded by the Norwegian military - and splash down in the Barents Sea, after which they are retrieved for analysis.

The middle and upper atmosphere is poorly understood, compared with the wellinvestigated troposphere and stratosphere. "We know little about turbulence, or about fluctuations in density and temperature," says ROMA's project leader Tom Blix, a space physicist at the Norwegian Defence Research Establishment in Kjeller, near Oslo.

The middle atmosphere is the coolest region of the Earth's atmosphere, reaching $-160{ }^{\circ} \mathrm{C}$ in polar regions in a layer called the mesopause, at an altitude of around 90 kilometres. Above this layer, temperatures rise again, and density decreases, through the ionosphere.

All of these layers are coupled, however, and the current global warming in the lower layers is expected to resonate throughout the atmosphere. A better understanding of the chemical and physical processes that take place at high altitudes may therefore help researchers to model long-term variations in climate.

But it is difficult to study the middle and upper atmosphere from the ground. Some researchers have sought to do so using pulsed laser instruments called LIDARs (light detection and ranging). The reflections of these lasers provide some information - about ice-particle concentrations, for example but do not tell researchers much about thermodynamic and electromagnetic processes that occur high in the sky.

"Only rocket-borne in situ measurements provide the highly resolved vertical snapshots that allow us to look for atmospheric fluctuations on all scales," says Blix.

Ny Ålesund is the northernmost perma-

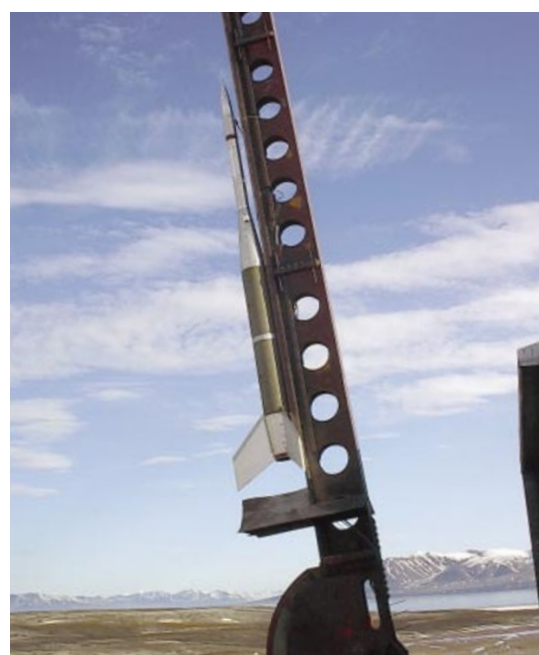

Sky high: the final rocket in the ROMA project prepares for blast-off from its Arctic launchpad.

nently inhabited village in the world. It is an ideal location for probing the upper atmosphere, says Markus Rapp, a physicist at the Leibniz Institute of Atmospheric Physics in Kühlungsborn, Germany, and a member of the ROMA team.

At the village's latitude of $79^{\circ} \mathrm{N}$, the force lines of the Earth's magnetic field are almost perpendicular to the Earth's surface, allowing ions from the solar wind to enter the atmosphere.

The ions have long been known to cause the northern lights, or aurora borealis, which are commonly observed at northern latitudes in winter. Free electrons, density fluctuations and the occurrence of ice clouds in the upper atmosphere also combine to produce radar phenomena called polar mesosphere summer echoes. These effects have only recently been explained (M. Rapp and F.-J. Lübken J. Geophys. Res. doi:10.1029/2002JD002857;2003).

The project is also tracking ionized ice particles in the upper atmosphere, which form 'noctilucent clouds' that are visible at dawn and dusk in modestly high latitudes, where the ice clouds scatter sunlight from below the horizon. Researchers believe that noctilucent clouds are linked to atmospheric radar echoes observed at high latitudes in summer.

ROMA's preliminary data have surprised its participants. "Density fluctuations and turbulence at high altitudes appear to be much stronger than we had expected," says Rapp.

But the cause of these fluctuations, and their impact on atmospheric science, have yet to emerge - the ROMA team is only now beginning to analyse its results.
Preliminary inquiry clears brain scientist of fraud allegation

\section{Alison Abbott, Munich}

An official investigation has cleared a prominent German neuroscientist of manipulating data in one of two scientific papers under scrutiny.

The allegations against Heinz Breer, a molecular neuroscientist at the University of Hohenheim in Stuttgart, were made earlier this year, prompting an investigation by the DFG, Germany's main funding agency. Breer says that his reputation has already been damaged by reports in German newspapers about the allegations (see Nature 422, 794; 2003).

The DFG's investigating committee this month issued an interim report on one of the two papers co-authored by Breer (S. Schreiber, J. Fleischer, H. Breer and I. Boekhoff J. Biol. Chem. 275, 24115-24123; 2000). It ruled that the paper contains "deficiencies of a technical nature", although it attributes these to sloppiness rather than an intention to mislead.

The paper is a study of the molecular processes by which the brain interprets odours. One apparent error identified by the committee relates to the analysis of data on the accumulation of a signalling molecule under different experimental conditions. The second involved mislabelling of negative controls in western blots - a method for identifying proteins separated by chromatography.

Breer, who won the prestigious Leibniz research award in 1998, has previously conceded minor problems with the paper. The experiments were mostly carried out by Ingrid Boekhoff, a young researcher in Breer's lab, and by an undergraduate student. The committee's report says the case "makes clear the importance of making young scientists familiar with the principles of good scientific practice". Boekhoff has agreed to send a correction to the Journal of Biological Chemistry.

Wieland Huttner, a molecular neurobiologist at the Max Planck Institute of Molecular Cell Biology and Genetics in Dresden, is one of two reviewers appointed by the DFG to investigate the case. He says that some of the data preparation was "sloppy", but that there is no evidence of cheating. He adds that the publicity surrounding the case, including German newspaper reports of the allegations, has been "unfair" to both Breer and Boekhoff.

The DFG committee is expected to rule on the second paper (J. Noé and H. Breer J. Neurochem. 71, 2286-2293; 1998) in the next few months. 